\title{
Brown Tumor of the Cervical Spines: A Case Report with Literature Review
}

\author{
Mohammad Dursi Alfawareh, Mohammed Mohamoud Halawani, \\ Walid Ismail Attia, Khaled Naser Almusrea \\ Spine Department, National Neuroscience Institute, King Fahad Medical City, Riyadh, Saudi Arabia
}

\begin{abstract}
To report a rare case of axis brown tumor and to review literature of cervical spine brown tumor. Brown tumor is a rare bone lesion, incidence less than $5 \%$ in primary hyperparathyroidism. It is more common in secondary hyperparathyroidism with up to $13 \%$ of cases. Brown tumor reactive lesion forms as a result of disturbed bone remodeling due to long standing increase in parathyroid hormones. Cervical spine involvement is extremely rare, can be confused with serous spine lesions. To date, only four cases of cervical spine involvement have been reported. Three were due to secondary hyperparathyroidism. Only one was reported to involve the axis and was due to secondary hyperparathyroidism. This is the first reported case of axis brown tumor due to primary hyperparathyroidism. A case report of brown tumor is presented. A literature review was conducted by a Medline search of reported cases of brown tumor, key words: brown tumor, osteoclastoma and cervical lesions. The resulting papers were reviewed and cervical spine cases were listed then classified according to the level, cause, and management. Only four previous cases involved the cervical spine. Three were caused by secondary hyperparathyroidism and one was by primary hyperparathyroidism which involved the C6. Our case was the first case of $\mathrm{C} 2$ involvement of primary hyperparathyroidism and it was managed conservatively. Brown tumor, a rare spinal tumor that presents with high PTH and giant cells, requires a high level of suspicion.
\end{abstract}

Keywords: Osteitis fibrosa cystica; Axis neoplasm; Osteoclastoma; Brown tumor; Hyperparathyroidism

\section{Introduction}

Brown tumor is a rare benign lesion of the bone, with incidence of less than $5 \%$ in primary hyperparathyroidism [1]. It is more common in secondary hyperparathyroidism, with up to $13 \%$ of cases [2,3]. Brown tumor is not a true tumor, it is a benign, unusual, reactive lesion as a result of disturbed bone remodeling, from long-standing increase in parathyroid hormone (PTH) level [4]. Spine involvement is unusual, and cervical spine involvement is extremely rare $[2,5]$. Brown tumor can be confused with more serious spine lesions, spine metastasis [6,7], leukemia, histeocytosis and other malignant spine tumors $[4,5]$.

There are only four cases of cervical spine involvement reported, three of which are of secondary hyperparathyroidism [4]. Only one reported case involves the axis, second cervical vertebra, in secondary hyperparathyroidism. To our knowledge, this is the first reported case of axis brown tumor due to primary hyperparathyroidism, a second reported for cervical spine involvement of primary hyperparathyroidism and a fifth reported cervical spine brown tumor.

Received Nov 7, 2013; Revised Dec 28, 2013; Accepted Jan 8, 2014

Corresponding author: Mohammad Dursi Alfawareh

Spine Departments, National Neuroscince Institute, King Fahad Medical City.

PO Box 59056, Riyadh, Saudi Arabia 11393

Tel: +9665679796976 Fax:+966114614006, E-mail: alfawarehm@yahoo.com 
The purpose of this study to report a rare case of the axis, second cervical vertebra (C2) brown tumor, due to primary hyperparathyroidism, and to conduct a literature review of cervical spine brown tumor, with its causes, pathology, pathogenesis, radiological criteria and management options.

\section{Case Report}

This is a case report of brown tumor that was managed at our institution. The literature review was conducted by the Medline search. Of all reported cases of brown tumor, the keywords searched were, brown tumor, osteoclastoma and cervical spine lesions.

The papers were extracted and reviewed, with the cases classified in one table. The cervical spine cases were listed and classified according to the level, cause and management.

\section{Case study}

A 26-year-old, female college student presented with a history of axial neck pain for one year. The pain had progressively increased and began radiating to both upper limbs for the past two months, with a mild weakness of the right-hand, leading to her emergency room visit.

On physical examination, the patient was intact neurologically, except for a mild weakness in the right-hand grip and hyper-reflexia. She had intact sensations in both upper and lower limbs. Cervical spine X-ray showed a lytic destructive lesion occupying the body of axis (second cervical vertebra) and dense (Fig. 1).

Computed tomography (CT) scan of the cervical spine showed expansile lytic lesion occupying most of the body of $\mathrm{C} 2$, odontoid process and left lateral mass, with extension to the transverse foramen displacing the left vertebral artery, but no thrombosis. A soft-tissue mass was founded and extended to the neuronal canal, causing about 50\% narrowing, with mild rotatory subluxation (Fig. 2).

Other incidental findings were expansile lytic lesion at the posterior aspect of left mandible and heterogeneous soft tissue mass at the neck, at the vicinity of the thyroid gland, about $1.5 \mathrm{~cm}$ in diameter.

The patient was admitted to our spine facility. Steroid was not considered at the start for several reasons: the pathology was not known (we thought it may change the pathology); and steroid was not part of our hospital protocol.

Magnetic resonance imaging (MRI) with contrast showed the lesion occupying most of the body of the axis lateral masses, which was dense and encased the left vertebral artery with soft tissue mass extension inside the neuronal canal, with moderate narrowing and paravertebral extension. The lesion showed mixed, heterogeneously hyperintense signals on T2 weighted images and iso- to hypointense on T1 weighted images, and stained heavily with contrast (Fig. 3).

Mandibular lesion showed the same MRI findings of C2 lesion. MR angiogram showed equal caliber vertebral arteries with normal outline, normal basilar artery and normal carotid arteries.
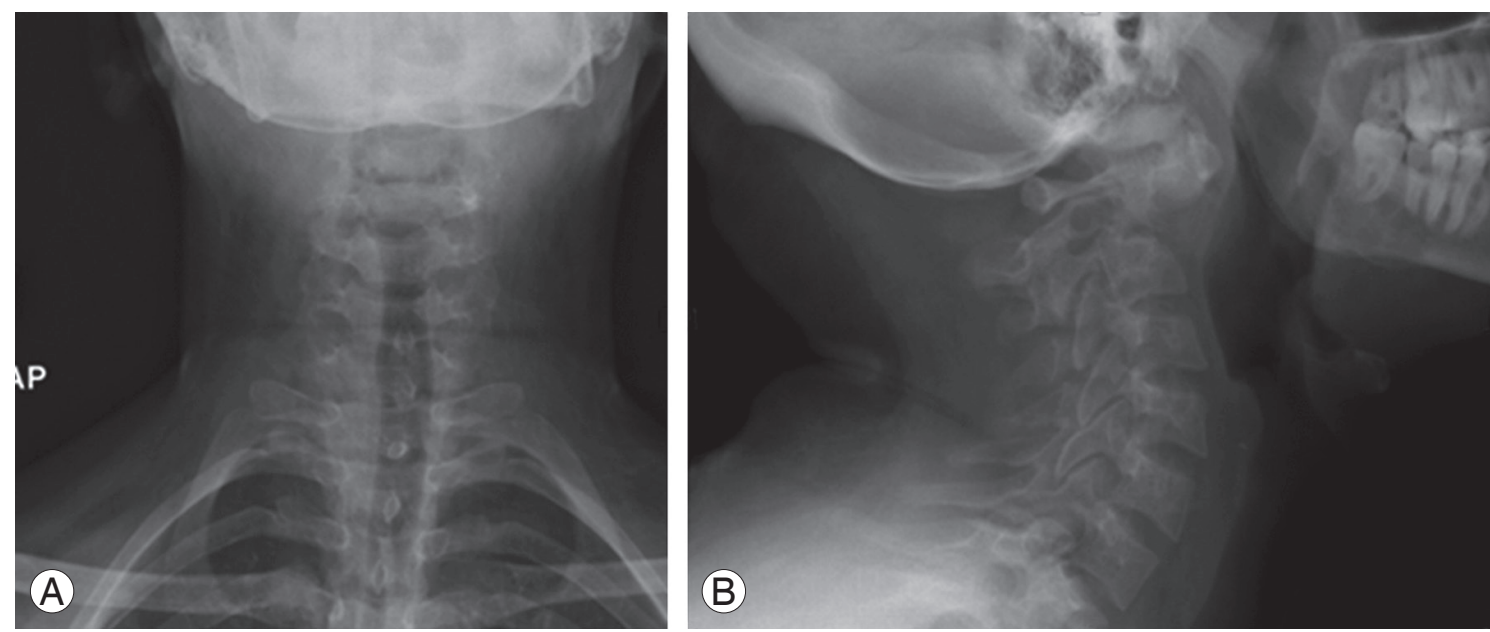

Fig. 1. (A, B) Posterioanterior and lateral X-ray of the cervical spine. 
Same MRI reconfirmed the CT findings, with heterogeneous signal intensity mass at the lower pole of right thyroid lobe (measuring $15 \times 28 \times 19 \mathrm{~mm}$ ). The mass was heterogeneous hyperintense on T2 weighted images and iso- to hypointense on T1 weighted images, with heterogeneous contrast enhancement, most likely representing
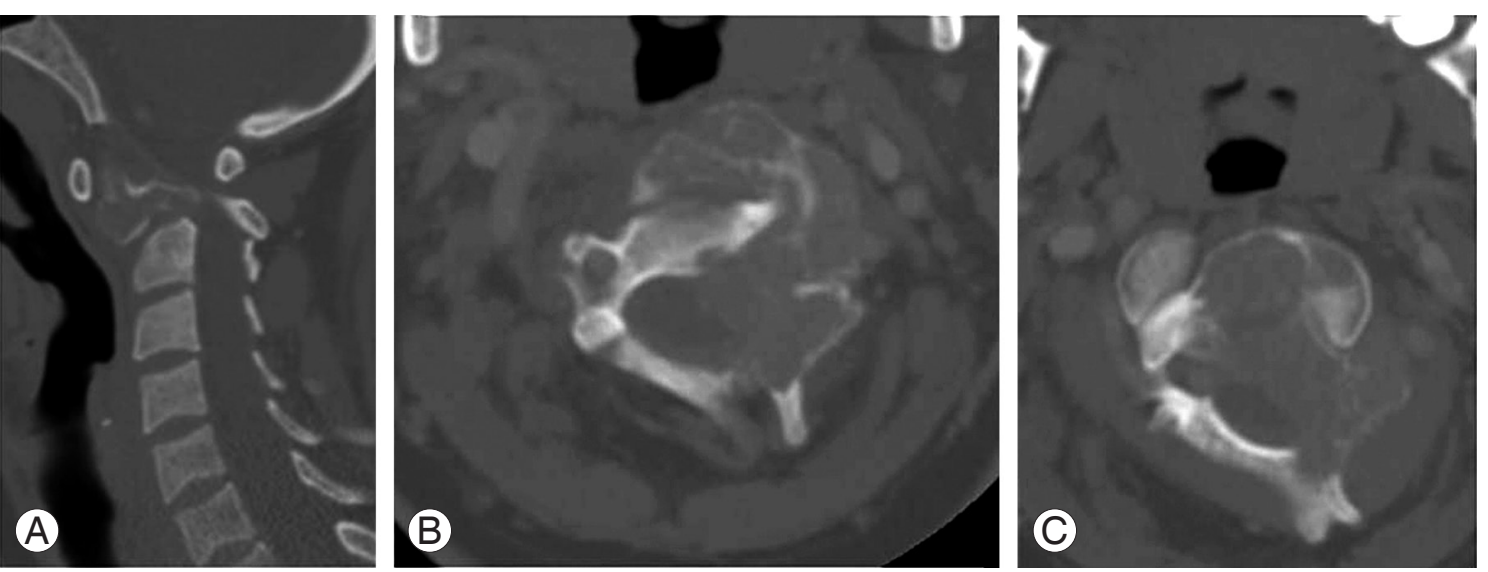

Fig. 2. (A-C) Sagittal and axial computed tomography scan of the upper cervical spine showing destructive lesion of the odontoid, body and lateral mass of $\mathrm{C} 2$ with atlantoaxial rotatory subluxation.
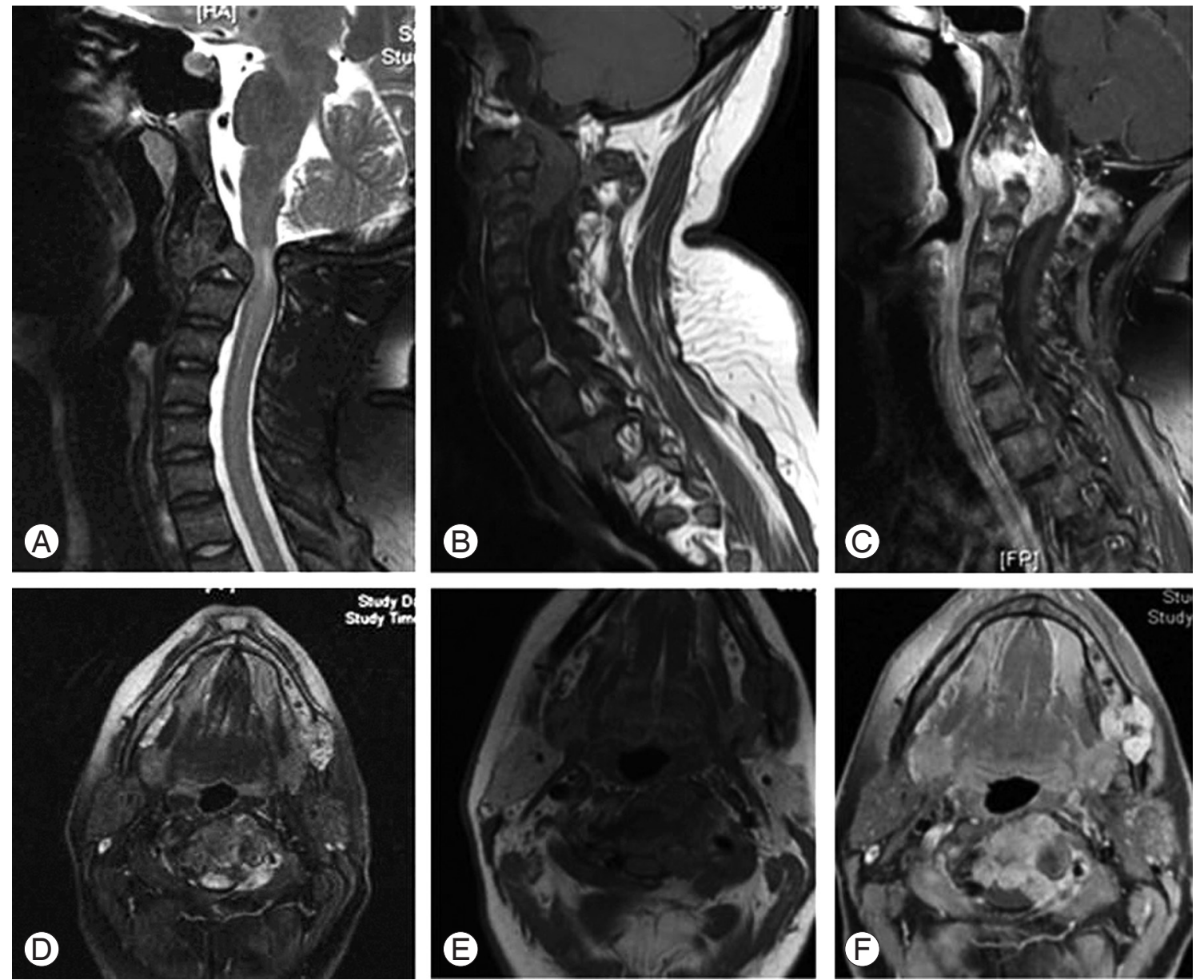

Fig. 3. (A-F) Axial and sagittal T1, T2, and T2 post contrast magnetic resonance imaging mages of the C2. 
a parathyroid adenoma.

Bone scan showed hyperactivity at the axis and left angle of mandible, neck, third lumbar vertebra and leftside iliac bone. Two abnormal focal lesions in the left side of C2 and left side of mandible corresponded to the lytic lesions seen on CT. The overall increased level of tracer uptake in the skull and extremities would also suggest a presence of metabolic bone disease. PTH was high at $64.4 \mathrm{pmol} / \mathrm{L}$ normal (normal, 1.6-6.9 pmol/L); corrected calcium level was high at $3.45 \mathrm{mmol} / \mathrm{L}$ (nor$\mathrm{mal}, 2.0-2.52 \mathrm{mmol} / \mathrm{L})$; serum phosphate was low at 0.53 $\mathrm{mmol} / \mathrm{L}$ (normal, $0.81-1.58 \mathrm{mmol} / \mathrm{L}$ ); vitamin D level was low at less than $10 \mathrm{nmol} / \mathrm{L}$ (normal, $28-110 \mathrm{mmol} /$ $\mathrm{L}$ ); and alkaline phosphatase was high at $268 \mathrm{U} / \mathrm{L}$ (normal, 50-136 U/L).

Parathyroid mass, high level of PTH and systemic findings in the bone scan raised the possibility of brown tumor of the bone, and biopsy was recommended. Interventional radiologist was consulted, and biopsy was done from the mandibular lesion, as C2 lesion was not feasible. The mandibular biopsy result showed some giant cells, but was not conclusive. Parathyroid mass aspiration was done concurrently, and the results were negative for malignancy and consistent with adenoma.

Surgical oncology was consulted to deal with parathyroid adenoma; and parathyroidectomy was recommended and done a week later. During the same operative session for parathyroidectomy, utilizing same surgical incision, with minimal blunt dissection, a true-cut biopsy of C2 lesion was done under C-arm fluoroscopy control Fig. 4.

Two weeks later, C2 biopsy results showed the following: fibrous lesion; increased osteoclastic activity; loss of bone trabeculae with accumulation of giant cells in fibrous stroma; hemosiderin accumulation; and no malignant cell, as consistent with giant cell tumor. This was reported by our local pathologist and also confirmed by another international pathology facility. Parathyroid mass pathology results were consistent with benign parathyroid adenoma.

In the first postoperative week, the patient's lab results were improved gradually. The PTH level decreased to $40.8 \mathrm{pmol} / \mathrm{L}$ in the first week and to normal three weeks later to 0.901 . The calcium level was decreased to 2.2 , phosphate level to 0.89 and alkaline phosphatase level to $114 \mathrm{U} / \mathrm{L}$.

Spine management was restricted to halo vest applica- tion for eight weeks; and halo vest was applied at the same time as parathyroidectomy. Conservative treatment was opted over surgical treatment, as the patient's symptoms were mild. There were dramatic improvements during the work-up period and approached normal after parathyroidectomy. Mild atlantoaxial rotatory subluxation was accepted, to avoid the patient the extensive major surgical reconstructive procedures.

Patient weakness was improved at the first postoperative week, the radicular pain disappeared in two weeks and axial pain was disappeared completely in two months. Halo vest was removed eight weeks later, and neck-collar was used for another four weeks then discontinued. Patient was followed up at an outpatient on regular bases. There were monthly cervical spine X-ray; and CT scan was repeated at three, six, twelve and twentyfour months follow-up.

Three-month follow-up CT scan showed a good level of calcification and filling of the lesion and advanced thoroughly thereafter. At two-year follow-up, CT showed near complete calcification and filling of the lesion, all over $\mathrm{C} 2$ body, odontoid and lateral masses (Fig. 5). Recurrence was monitored by MRI at three, six, twelve and twenty-

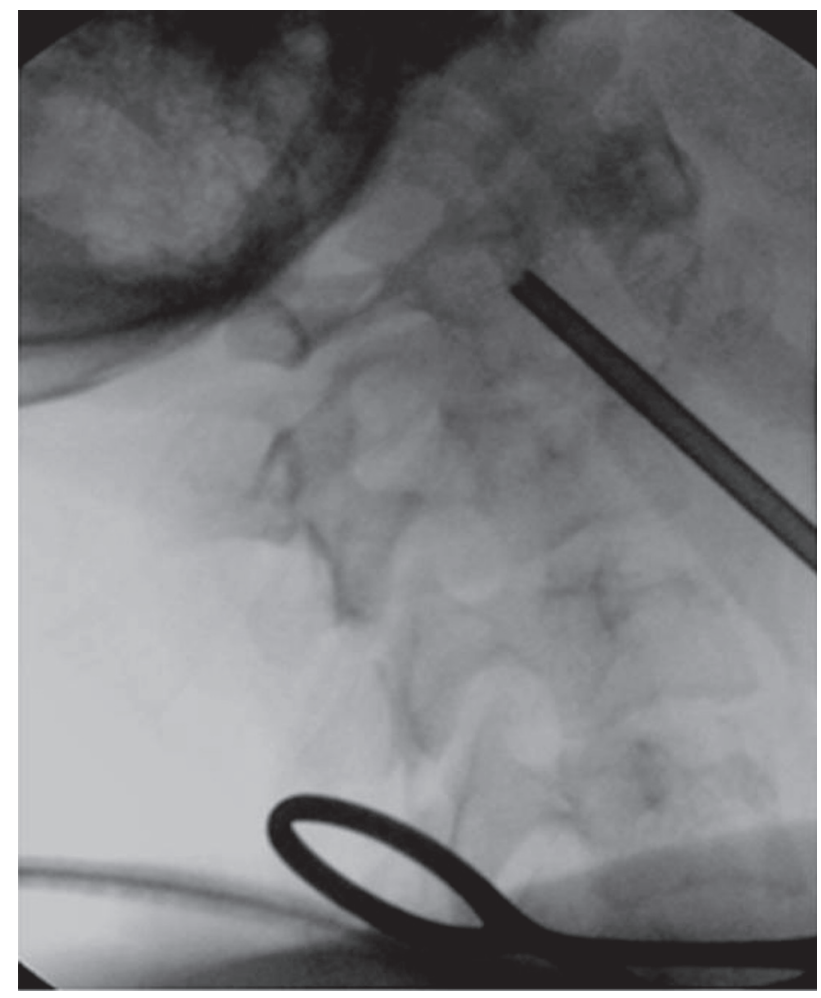

Fig. 4. Fluoroscopy image demonstrating biopsy. 
four months; and there was no evidence of recurrence or neurological compromise (Fig. 6). PTH and calcium levels were followed up by endocrinologist on regular basis, and was remained well-controlled at final follow-up.

At two-year final follow-up, the patient had no complaints. The neurological examination was intact, with almost complete calcification of the lesion and normal labs. The patient maintained a good range of neck motion, although she maintained mild atlantoaxial rotatory subluxation (Fig. 7).

\section{Discussion}

Brown tumor, also known as osteoclastoma [8], is a rare benign lesion of the bone. The incidence ranges from 1.5\% in primary hyperparathyroidism [1,9] to $13 \%$ in cases of secondary hyperparathyroidism due to chronic renal failure $[2,3,10]$. Brown tumor is not a true tumor; it is a benign, unusual reactive lesion as a result of disturbed bone remodeling, due to long-standing increase in PTH level, an extreme form of ostitis fibrosa cystica [4].

Bone involvement, usually focal lytic lesion, has a pre-
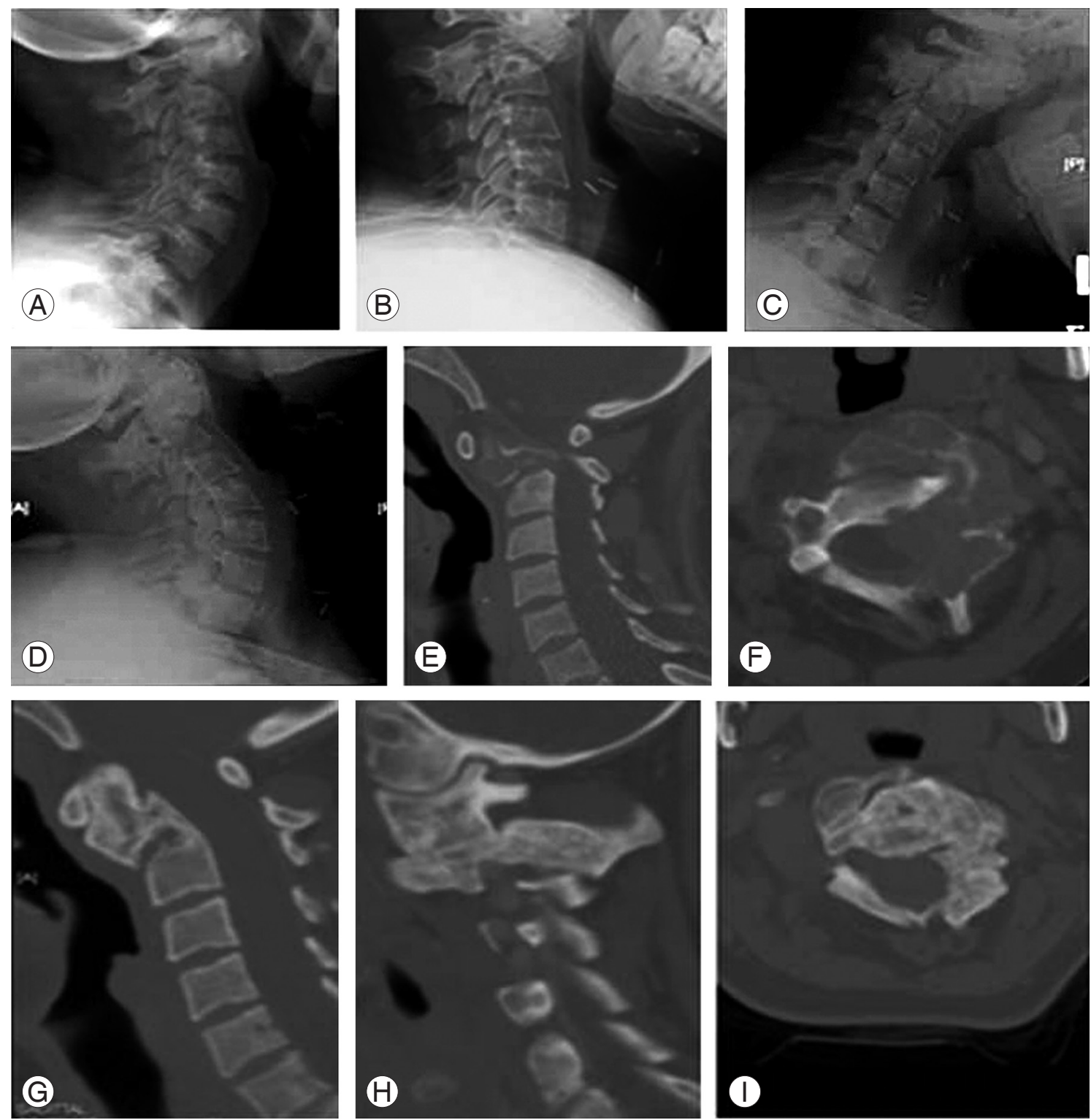

Fig. 5. (A-I) Two years follow up X-ray of the cervical spine demonstrating complete calcification of C2, flexion extension X-ray demonstrating no instability, lower row demonstrating computed tomography scan at time of diagnosis and at 2 years follow up. 
dilection for facial and mandibular bones, but can occur at any bone $[9,11]$. Spine involvement is very rare [12], and can require urgent surgery to prevent serious neurological complications $[5,13]$. Cervical spine involvement is extremely rare [2,5], with only one reported case of the axis involvement [5].

To date only four cases of cervical spine involvement
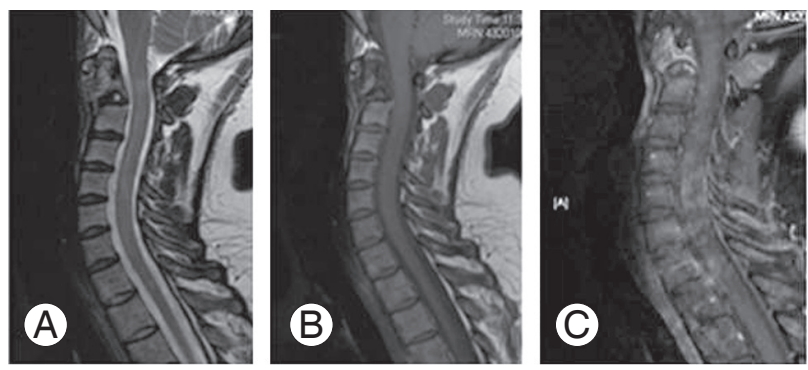

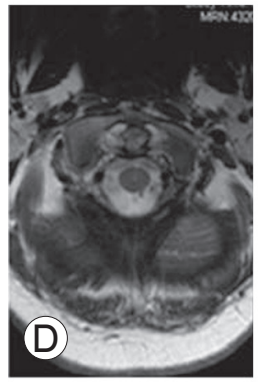

T2

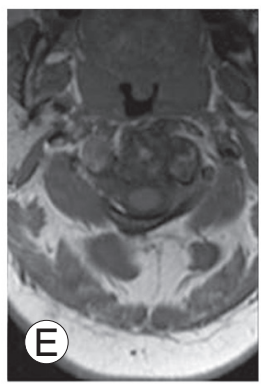

T1

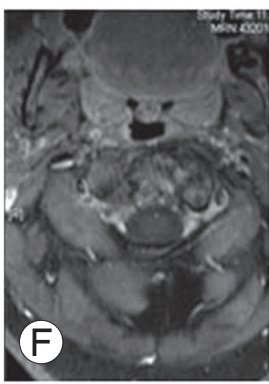

$\mathrm{T} 1+\mathrm{C}$
Fig. 6. (A-F) Two years follow up magnetic resonance imaging of the cervical spine, complete resolution of the mass. have been reported, three of them due to secondary hyperparathyroidism [5], an involvement of axis. The second cervical vertebra involvement has been reported once to our knowledge; and this is the second reported case of brown tumor involving the axis. It is the first case of axis-involvement due to primary hyperparathyroidism, and the second case of cervical spine involvement with primary hyperparathyroidism.

More spine brown tumors occur in secondary hyperparathyroidism [14]. Secondary hyperparathyroidism is usually due compensatory hyper secretion of PTH by any cause of calcium level suppression, the most common being chronic renal failure, inadequate intake and vitaminD deficiency [15]. Clinical presentation of brown tumor may be related to the elevated level of calcium and bone symptoms [16], like bone pain. Neurological symptoms depend on compromised neuronal structures [15]. Brown tumor is usually a slow-growing tumor, and presentation depends on the anatomical site of the tumor. Spine involvement is usually presented with pain; and neurological deficit and weakness are also reported $[3,8,9]$.

In the present case, the patient was presented with neck pain for several months and radicular pain for two months, a typical presentation of mass or lesion occupying the spine that affects stability and compromises the neuronal element. Although the mass did affect destruction of $\mathrm{C} 2$, with sizable intra spinal extension, it main-
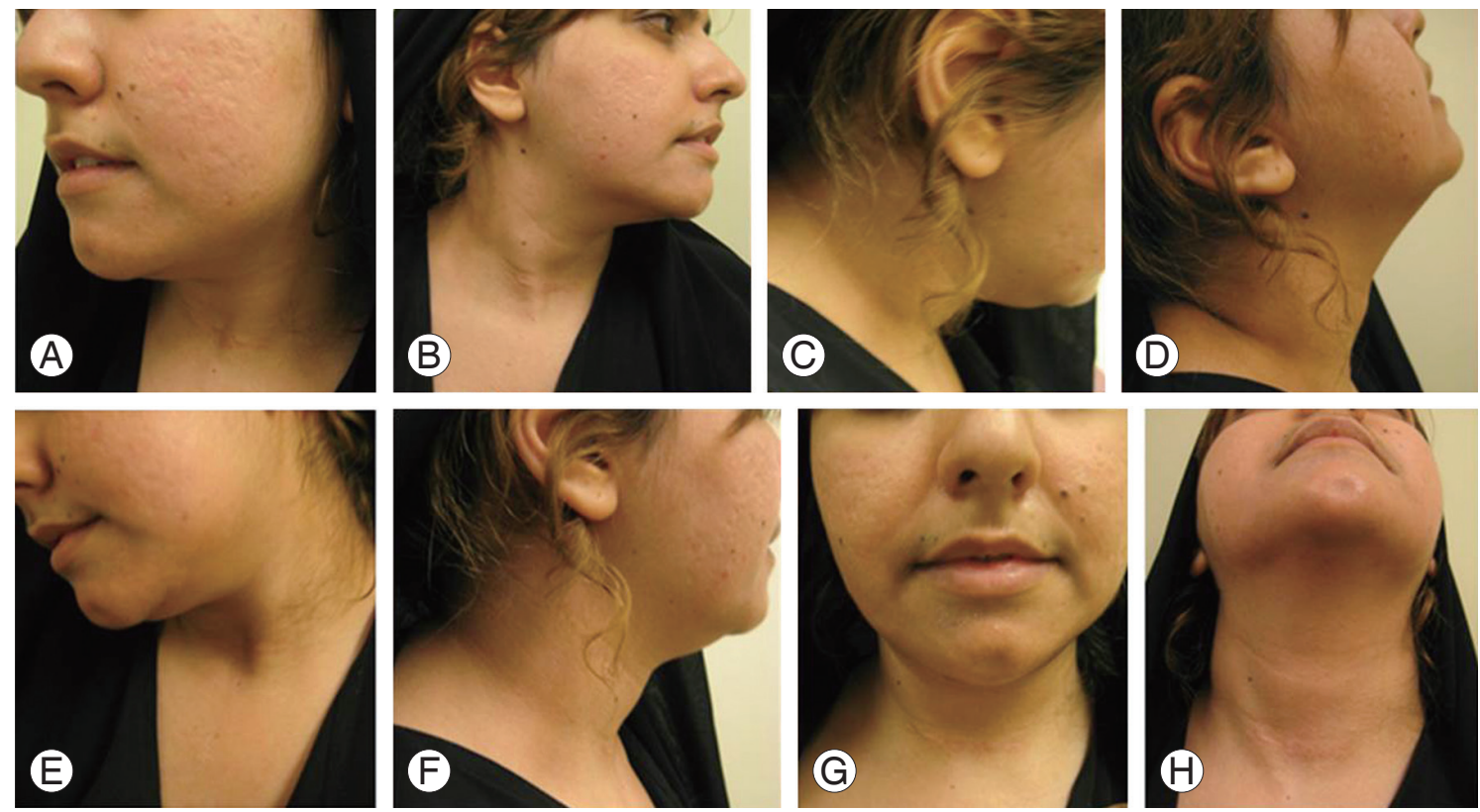

Fig. 7. (A-H) Clinical photos of the patient, demonstrating good range of motion in all directions flexion, extension, lateral bending and rotation. 
tained intact neurological exam, apart from the mild grip weakness.

Pain can be explained by the pathophysiology of brown tumor. A high level of PTH leads to increased osteoclastic activity, with reactive fibroblastic proliferation of the involved bone, which results in a loss of bone trabeculae [8]. It predisposes to microfractures and secondary hemorrhage, which may explain the pain. It leads to influx of macrophages or giant osteoclastic cells, and an ingrowth or reparative fibrous tissue (a reactive tissue mass known as brown tumor), and may encroach neuronal structures leading to neuropathy and/or weakness, as in our case [15-17]. Cystic degeneration is not uncommon [15-17]. Vascularity, hemorrhage and hemosiderin deposition give it the characteristic color.

Our patient was admitted to the spine facility. Steroid was not considered, as it is not part of our hospital protocol (steroid may change the pathological picture of bone tumor), and also the patient's symptoms were mild.

A simple X-ray of the patient's spine demonstrated a lytic lesion occupying $\mathrm{C} 2$ and odontoid with mild $\mathrm{C} 1-$ C2 instability, which were close to the typical findings; i.e., expansile lytic lesion [18], sharp outlines, no sclerotic margins [13], with lobulated appearance, possible destruction of the vertebra [15], without invading soft tissue [5] and skeletal survey detecting other lesions in mandible, lumbar spines and ilium.

CT scan characteristics of brown tumor are expansile lytic lesions, with various amounts of bone destruction and thinning of trabeculae $[5,15]$. In our case, the lesion was occupying odontoid, body and lateral mass of C2 with ballooning and cortical thinning.

MRI scan may show iso-intense to hypo-intense lesion on T1-weighted imaging and hyper-intense on T2 weighted imaging and STIR, with uptake of contrast and soft tissue expansion over neuronal canal $[15,19]$. In our case, there was demonstrated mixed signal intensity of $\mathrm{T} 2$ and hypointense on T1series, with mass extension in the neuronal canal, and at the same time demonstrating parathyroid mass. As such, neck US was done to evaluate the parathyroid mass. Neck MRI evaluates the parathyroid mass, size, site and enactment of contrast, and may differentiate the benign from malignant.

Because of the hypervascularity of the lesion, in three phases, the bone scan usually shows increased uptake and enhancement in all three phases. It may indicate regional perfusion, osteoid formation and mineralization [20], and multiple locations may also be detected [5]. In our case, the bone scan detected other lesions in lumbar spine and pelvis.

Laboratory tests usually show elevated PTH, often more than 10 -times the normal $[10,14,15]$, alkaline phosphatase, high to normal serum calcium and low serum phosphate [21]. In the present case, the PTH level was very high at $64.4 \mathrm{pmol} / \mathrm{L}$ (normal, 1.6-6.9 pmol/L), with high calcium level at $3.45 \mathrm{mmol} / \mathrm{L}$ (normal, $2.0-2.52 \mathrm{mmol} / \mathrm{L}$ ), low phosphate at $0.53 \mathrm{mmol} / \mathrm{L}$ (normal, $0.81-1.58$ ) and low vitamin-D at less than $10 \mathrm{nmol} / \mathrm{L}$ (normal, 28-110 $\mathrm{nmol} / \mathrm{L})$.

Open or image-guided biopsy is usually indicated to finalize the diagnosis, since laboratory findings are not totally reliable for definite diagnosis [21]. In our case CT guided biopsy was tried from the mandibular lesion, but was not diagnostic.

Parathyroid adenoma is the most common cause in primary hyperparathyroidism, and other causes include parathyroid carcinoma and hyperplasia $[8,22,23]$. Surgical oncology was consulted, and parathyroidectomy was recommended and done. During the surgery, we utilized the same approach and did image guided true-cut biopsy of the lesion (Fig. 4). Pathological findings of brown tumor are gross appearance showing cystic mass and brown in color, with hemorrhagic and fibrotic areas.

On microscopic examination, brown tumor shows the following characteristics. There are increased osteoclasts activity and bone resorption [9]; increased bone formation and osteoblastic activity; and bony trabeculae tending to be shrunken and irregular with increased osteoclastic resorption, producing a small hole. In tunneling or dissecting, it becomes confluent with others to create a brown tumor [24], localized paratrabecular and marrow fibrosis, not diffused fibrosis as in myelofibrosis [13], multinucleated giant cells that are arranged in clusters and interstitial hemorrhage with hemosiderin deposition [5]. There are infrequent mitosis [25,26], without anaplastic or pleomorphic cells [4].

Our C2 biopsy results showed fibrous lesion, increased osteoclastic activity, loss of bone trabeculae with accumulation of giant cells in fibrous stroma, with hemosiderin accumulation and no malignant cells, as consistent with giant cell tumor. This was reported by our local pathologist and confirmed by another international facility.

Brown tumor should be differentiated from aneurysmal one cyst, giant cell tumor, myeloma, Paget's disease [19], 
Langerhans cell histiocytosis, multiple myeloma [5] and metastasis $[13,18]$.

There may be no solid histological criteria to differentiate giant cell tumors [8]. The stromal spindle cells appear more swollen; and giant cells are regularly distributed, not in clusters, and there is no interstitial hemorrhage $[13,19]$. Aneurysmal bone cyst usually affects the younger aged population, with cyst fluid levels on the MRI [15]. In Paget's disease, osteoclast is generally located at the surface of bone, while in brown tumor it is usually found deep in the bone, forming tunnels $[13,19]$. A high level of PTH may be the only clue [8].

Treatment of brown tumor depends on the underlying cause of high PTH. A prevention of chronic renal failure is done with appropriate calcium and vitamin-D supplement [15]. A high level of PTH needs to have dynamic changes in the bone. Other factors may contribute to the bone changes, including high calcium concentrate dialysate, use of large doses of calcium-containing phosphate binder, inappropriate use of vitamin-D sterol, peritoneal dialysis and aluminum toxicity [15,27]. Adenoma resection in primary hyperparathyroidism is the standard treatment, with rapid increase in bone mineral density as early as one week post parathyroidectomy and up to $100 \%$ in one year [2,28-30]. Such was well demonstrated in the presented case. The PT level was dropped to near normal during the first postoperative week, with a dramatic improvement of symptoms.

In patients without evidence of spinal cord compression, tumor usually regresses [31], and clinical symptoms are resolved shortly after parathyroidectomy (usually within the first week up to six months [4]). Stability is restored as lesion is gradually mineralized thereafter, in up to one year [12], and addition of bisphosphonate before or after surgery may help [13]. This was the scenario in the present case, where the labs were normalized after parathyroidectomy, the radicular pain was improved during the second week, and neck pain thereafter.

Vitamin-D, alpha calcidiol or clacitriol daily doses can reduce level of PTH and promote tumor regression [32]. There is a range of spine management: observation, when there is no cord compression or stability concern; orthotic or external fixation like Halo Vest; and surgical decompression, as indicated by neurological symptoms or instability [33]. Spine reconstruction with fusions may be indicated [9]. Such may be challenging, due to generalized osteoporosis [13]. A complete resection of the tumor is not mandatory [22], and preoperative embolization may be necessary [15].

To choose between conservative and surgical management may be challenging, due to the rarity of the tumor and literature discussing the management. The natural history usually regresses and a complete ossification will happen after parathyroidectomy. This option is valid when the patient is neurologically intact or has mild symptoms, with stable spines $[9,22,23]$. If conservative management is chosen, a careful monitoring and close follow-up is needed to prevent any neurological compromise and/or instability that can lead to catastrophic results.

We opted for conservative management for our patient, as her symptoms were mild, with no weakness apart from mild grip weakness. Pain was dramatically improved after parathyroidectomy, and stabilization was managed by halo vest. Mild atlantoaxial instability was accepted to void major surgical reconstruction. At two-year followup, there was complete clinical improvement, with near total calcification of the lesion and satisfactory results.

Surgery is usually indicated by severe symptoms, major neurological defect, failure of conservative management and instability [9]. Decompression and/or fusion may be considered, and approach should be considered carefully depending on the tumor size, tumor location, surgeon experience, preference and the ability to decompress the nerves and restore the stability at the same time. Posterior decompression with or without fusion may resolve the symptoms, but may not achieve complete resection of odontoid mass.

When necessary, corpoctomy and reconstruction via anterior submandibular approach is another option. The anterior approach, although technically demanding, provides excellent exposure, with near complete excision of the odontoid tumor and the ability to reconstruct and instrument the spine, providing immediate excision and stability [13]. Transoral approach can provide excision of the tumor, but no fixation can be used. A combined anterior and posterior approach may be needed.

In Kaya et al's [13] review article, only fourteen cases were reported of secondary hyperparathyroidism, with spine involvement. Most of the cases were thoracic, with only one cervical and one cervicothoracic. Four of the cases were managed conservatively, and nine were managed surgically; four with anterior corpoctomy and reconstruction, five with posterior decompression and 
Table 1. Brown tumor of cervical spine brown

\begin{tabular}{|c|c|c|c|c|c|c|c|}
\hline No. & Year & Author & $\begin{array}{l}\text { Vertebra } \\
\text { involved }\end{array}$ & $\begin{array}{l}\text { Age } \\
\text { (yr) }\end{array}$ & Sex & $\begin{array}{c}\text { Cause of } \\
\text { hyperparathyroidism }\end{array}$ & Treatment \\
\hline 1 & 1978 & Ericsson et al. [34] & $\mathrm{C} 7-\mathrm{T} 1$ & 47 & Female & Secondary & $\begin{array}{l}\text { Parathyroidectomy } \\
\text { Tumor resection } \\
\text { Spine reconstruction }\end{array}$ \\
\hline 2 & 1993 & Barlow and Archer [29] & - & 31 & Female & Secondary & $\begin{array}{l}\text { Parathyroidectomy } \\
\text { Orthosis }\end{array}$ \\
\hline 3 & 2002 & Ashebu et al. [35] & C6 & 27 & Female & Primary & Parathyroidectomy \\
\hline 4 & 2010 & Mateo et al. [5] & C2 & 37 & Female & Secondary & $\begin{array}{l}\text { Parathyroidectomy } \\
\text { Orthosis }\end{array}$ \\
\hline 5 & 2013 & Alfawareh (current study) & C2 & 26 & Female & Primary & $\begin{array}{l}\text { Parathyroidectomy } \\
\text { Orthosis }\end{array}$ \\
\hline
\end{tabular}

fusion and one with decompression only [13].

In literature review of Mateo et al. [5], only nine cases were reported of primary hyperparathyroidism with spine involvement, six of them thoracic, two sacral, one lumbar and none cervical. Of the cases, four were treated by surgical parathyroidectomy, two received medical treatment and the rest were treated surgically, with either anterior, posterior or combined approaches [5]. Patients without neurological compression were successfully managed by parathyroidectomy.

In Mustonen et al. [3] review (2004), seven cases of brown tumor were reported as a result of primary hyperparathyroidism, six were thoracic, none lumbar and only one was cervical and involving C6. This case was not included in Mateo's review [3]. In the same review, nine cases of secondary hyperparathyroidism were reported with spine involvement, six thoracic, one lumbar and two cervical [3].

When combining all cases of the reviews, a total of twenty-five cases, only four were cervical [5], and only one case involved second cervical vertebra. Our case is the second reported case involving axis and fifth for cervical spine brown tumor (Table 1).

Four cases of brown tumor involving cervical spine have been reported. Of these, only the first one case was caused by primary hyperparathyroidism and involved C6 [35]. The other three were caused by secondary hyperparathyroidism [3]. The second case was reported by Ericsson et al. [34] with C7-T1 involvement; the third case was reported by Barlow and Archer [29] with C5 involvement; and the last case was reported by Mateo et al. [5], involving $\mathrm{C} 2$.

To our knowledge, our case is the first reported case of
C2 involvement, caused by primary hyperparathyroidism, the second case of cervical spine involvement due to the primary hyperparathyroidism and the fifth reported case of cervical spine brown tumor.

Brown tumor is a rare manifestation of hyperparathyroidism, which is more common with secondary than primary hyperparathyroidism. Spine involvement is extremely rare, and thoracic spine may be the most common site of spine involvement. In cervical spine, it can be manifested by pain or neurological symptoms. A high level of PTH may be the only clue when there is no instability or neurological compression. There may be a complete recovery of symptoms, with lesion calcification, and filling can occur after parathyroidectomy with or without medical hormonal management.

\section{Conflict of Interest}

No potential conflict of interest relevant to this article was reported.

\section{References}

1. Haddad FH, Malkawi OM, Sharbaji AA, Jbara IF, Rihani HR. Primary hyperparathyroidism. A rare cause of spinal cord compression. Saudi Med J 2007;28:7836.

2. Jackson W, Sethi A, Carp J, Talpos G, Vaidya R. Unusual spinal manifestation in secondary hyperparathyroidism: a case report. Spine (Phila Pa 1976) 2007;32:E557-60.

3. Mustonen AO, Kiuru MJ, Stahls A, Bohling T, Kivioja A, Koskinen SK. Radicular lower extremity pain as 
the first symptom of primary hyperparathyroidism. Skeletal Radiol 2004;33:467-72.

4. Hoshi M, Takami M, Kajikawa M, et al. A case of multiple skeletal lesions of brown tumors, mimicking carcinoma metastases. Arch Orthop Trauma Surg 2008;128:149-54.

5. Mateo L, Massuet A, Sola M, Perez Andres R, Musulen E, Sanchez Torres MC. Brown tumor of the cervical spine: a case report and review of the literature. Clin Rheumatol 2011;30:419-24.

6. Hsieh MC, Ko JY, Eng HL. Pathologic fracture of the distal femur in osteitis fibrosa cystica simulating metastatic disease. Arch Orthop Trauma Surg 2004;124:498-501.

7. Joyce JM, Idea RJ, Grossman SJ, Liss RG, Lyons JB. Multiple brown tumors in unsuspected primary hyperparathyroidism mimicking metastatic disease on radiograph and bone scan. Clin Nucl Med 1994;19:630-5.

8. Vandenbussche E, Schmider L, Mutschler C, Man M, Jacquot C, Augereau B. Brown tumor of the spine and progressive paraplegia in a hemodialysis patient. Spine (Phila Pa 1976) 2004;29:E251-5.

9. Altan L, Kurtoglu Z, Yalcinkaya U, Aydinli U, Erturk E. Brown tumor of the sacral spine in a patient with low-back pain. Rheumatol Int 2007;28:77-81.

10. Tarrass F, Ayad A, Benjelloun M, et al. Cauda equina compression revealing brown tumor of the spine in a long-term hemodialysis patient. Joint Bone Spine 2006;73:748-50.

11. Deal C. The endocrine system, clinical presentation of rheumatic disease. In: Maddison PJ, Isenberg DA, Woo P, Glass DN, editors. Oxford textbook of rheumatology. Oxford: Oxford Univ. Press; 1998. p.277-8.

12. Azria A, Beaudreuil J, Juquel JP, Quillard A, Bardin T. Brown tumor of the spine revealing secondary hyperparathyroidism. Report of a case. Joint Bone Spine 2000;67:230-3.

13. Kaya RA, Cavusoglu H, Tanik C, et al. Spinal cord compression caused by a brown tumor at the cervicothoracic junction. Spine J 2007;7:728-32.

14. Pecovnik Balon B, Kavalar R. Brown tumor in association with secondary hyperparathyroidism. A case report and review of the literature. Am J Nephrol 1998;18:460-3.

15. Mak KC, Wong YW, Luk KD. Spinal cord compression secondary to brown tumour in a patient on long-term haemodialysis: a case report. J Orthop Surg (Hong Kong) 2009;17:90-5.

16. Maitra A, Abbas AK. The endocrine system. In: Kumar V, Abbas AK, Fausto N, Robbins SL, Cotran RS, editors. Robbins and Cotran pathologic basis of disease. Philadelphia: Elsevier Saunders; 2005. p.1155226.

17. Roenberg A. Bones, joints, and soft tissue tumors. In: Kumar V, Abbas AK, Fausto N, Robbins SL, Cotran RS, editors. Robbins and Cotran pathologic basis of disease. Philadelphia: Elsevier Saunders; 2005. p.1273-324.

18. Chew FS, Huang-Hellinger F. Brown tumor. AJR Am J Roentgenol 1993;160:752.

19. Fineman I, Johnson JP, Di-Patre PL, Sandhu H. Chronic renal failure causing brown tumors and myelopathy. Case report and review of pathophysiology and treatment. J Neurosurg 1999;90:242-6.

20. Jordan KG, Telepak RJ, Spaeth J. Detection of hypervascular brown tumors on three-phase bone scan. J Nucl Med 1993;34:2188-90.

21. Al-Gahtany M, Cusimano M, Singer W, Bilbao J, Kovacs K, Marotta T. Brown tumors of the skull base. Case report and review of the literature. J Neurosurg 2003;98:417-20.

22. Erturk E, Keskin M, Ersoy C, Kaleli T, Imamoglu S, Filiz G. Metacarpal brown tumor in secondary hyperparathyroidism due to vitamin-D deficiency. A case report. J Bone Joint Surg Am 2005;87:1363-6.

23. Jeren-Strujic B, Rozman B, Lambasa S, Jeren T, Markovic M, Raos V. Secondary hyperparathyroidism and brown tumor in dialyzed patients. Ren Fail 2001;23:279-86.

24. Ganesh A, Kurian S, John L. Complete recovery of spinal cord compression following parathyroidectomy. Postgrad Med J 1981;57:652-3.

25. Shaw MT, Davies M. Primary hyperparathyroidism presenting as spinal cord compression. Br Med J 1968;4:230-1.

26. Sundaram M, Scholz C. Primary hyperparathyroidism presenting with acute paraplegia. AJR Am J Roentgenol 1977;128:674-6.

27. Hernandez JD, Wesseling K, Salusky IB. Role of parathyroid hormone and therapy with active vitamin D sterols in renal osteodystrophy. Semin Dial 2005;18:290-5.

28. Agarwal G, Mishra SK, Kar DK, et al. Recovery pat- 
tern of patients with osteitis fibrosa cystica in primary hyperparathyroidism after successful parathyroidectomy. Surgery 2002;132:1075-83.

29. Barlow IW, Archer IA. Brown tumor of the cervical spine. Spine (Phila Pa 1976) 1993;18:936-7.

30. Bohlman ME, Kim YC, Eagan J, Spees EK. Brown tumor in secondary hyperparathyroidism causing acute paraplegia. Am J Med 1986;81:545-7.

31. Bassler T, Wong ET, Brynes RK. Osteitis fibrosa cystica simulating metastatic tumor. An almost-forgotten relationship. Am J Clin Pathol 1993;100:697-700.

32. Arabi A, Khoury N, Zahed L, Birbari A, El-Hajj Fuleihan G. Regression of skeletal manifestations of hyperparathyroidism with oral vitamin D. J Clin En- docrinol Metab 2006;91:2480-3.

33. Pumar JM, Alvarez M, Perez-Batallon A, Vidal J, Lado J, Bollar A. Brown tumor in secondary hyperparathyroidism, causing progressive paraplegia. Neuroradiology 1990;32:343.

34. Ericsson M, Holm E, Ingemansson S, Lindholm T, Svendgaard NA. Secondary hyperparathyroidism combined with uremia and giant cell containing tumor of the cervical spine. A case report. Scand J Urol Nephrol 1978;12:185-7.

35. Ashebu SD, Dahniya MH, Muhtaseb SA, Aduh P. Unusual florid skeletal manifestations of primary hyperparathyroidism. Skeletal Radiol 2002;31:720-3. 